\title{
SIMULTANEOUS VOLTAMMETRIC DETERMINATION OF N-ACETYL-L-CYSTEINE, URIC ACID AND TRYPTOPHAN AT SURFACE OF GLASSY CARBON ELECTRODE IN THE PRESENT OF 4-CHLOROCATECHOL AS A HOMOGENEOUS ELECTROCHEMICAL CATALYST
}

\author{
BITA JAHANSHAHI, JAHANBAKHSH RAOOF ${ }^{*}$, MOHADDESEH AMIRI-AREF, REZA OJANI
}

Electroanalytical Chemistry Research Laboratory, Department of Analytical Chemistry, Faculty of Chemistry, University of Mazandaran, Babolsar, Iran

\begin{abstract}
Simultaneous determination of N-acetyl-L-cysteine (NAC), uric acid (UA) and tryptophan (Trp) has been studied at the surface of glassy carbon electrode (GCE) in the present of 4-chlorocatechol as a homogenous electrochemical catalyst in aqueous media. The electrocatalytic properties of GCE in the present of 4-chlorocatechol toward the electrocatalytic oxidation of NAC, UA and Trp was studied using cyclic voltammetry (CV), double-step potential chronoamperometry and differential pulse voltammetry (DPV). The results show that NAC participates in the reaction with electrogenerated quinone from electrooxidation of 4-chlorocatechol at surface of GCE to form the corresponding thioquinone derivative. The reoxidation of the adduct leads to increase in the oxidative current which is proportional to the concentration of NAC. Differential pulse voltammogram peak currents of NAC, UA and Trp increased linearly with their concentrations in the ranges of $5.0-45.0 \mu \mathrm{M}, 10.0-50.0 \mu \mathrm{M}$ and $5.0-55.0 \mu \mathrm{M}$, respectively and the detection limits for NAC, UA and Trp were sequentially $3.55 \mu \mathrm{M}, 6.96 \mu \mathrm{M}$ and $4.41 \mu \mathrm{M}$. The proposed method was employed for simultaneous determination of NAC, UA and Trp in the pharmaceutical and biological samples and the obtained results were found to be satisfactory.
\end{abstract}

Key Words: N-acetyl-L-cysteine; Uric acid; Tryptophan; 4-Chlorocatechol.

\section{INTRODUCTION}

$\mathrm{N}$-acetyl-L-cysteine (NAC) is the acetylated form of L-cysteine, as an amino acid ${ }^{1}$. NAC institutes an excellent source of sulphydryl groups ( $\mathrm{SH}$ ), which is switched in organism into metabolites capable to stimulate the synthesis of reduced glutathione $(\mathrm{GSH})^{2}$. NAC is a great antioxidant to acts as a potentially therapeutic agent in the treatment of cardiovascular, respiratory diseases $^{3}$, cancer $^{4}$ and human immunodeficiency virus (HIV) infection ${ }^{5}$ ${ }^{6}$, acetaminophen toxicity ${ }^{7}$, and other diseases. A great deal of analytical methods such as spectrophotometry ${ }^{8-11}$, chromatography $y^{12-14}$ and fluorimetry ${ }^{15}$ has been developed for the determination of $\mathrm{N}$-acetyl-L-cysteine. However, these methods often require time spending complex pretreatment steps and their apparatus and operating cost are too expensive for routine analysis. Compared to these options, in analytical methods, electrochemical detection is an attractive method due to its simplicity, low expense and high sensitivity ${ }^{16}$.

Uric acid (UA) is the primary product of catabolism of the purine ${ }^{17}$. Abnormal concentration level of UA in the body may be symptoms of several diseases, including gout, hyperuricaemia, and Lesch-Nyan syndrome ${ }^{18}$. So it is desirable to have a simple and direct method for determination of UA in pharmaceutical and biological samples. Individual determination of UA has been reported with other techniques ${ }^{19-23}$. Comparing with other techniques, electrochemical methods have received much interest because of its selectivity, convenience and low $\cos ^{24}$.

Tryptophan (Trp) is necessary amino acid for human and Herbivores to plays an essential role in brain functions and related regulatory mechanisms. It is sometimes added to dietary as food products and to pharmaceutical formulations in due to correct possible dietary deficiencies ${ }^{25}$. Trp is a vital constituent of proteins, the analysis of Trp is great importance in the pharmaceutical and dietetic fields as they are precursor molecules of hormones, a precursor of the neurotransmitter serotonin and other relevant bimolecular ${ }^{26}$. To date, several techniques have been reported for the determination of Trp in various samples. Some of these techniques are liquid chromatography ${ }^{27}$, spectrophotometric procedures ${ }^{28}$ and capillary electrophoresis ${ }^{29}, 30$, but electrochemical methods have the advantages of high sensitivity, low cost and simple instruments, for determination of $\operatorname{Trp}^{31}$.

4-Chlorocatechol has been used as an electron transfer mediator in electrochemical processes due to their high electron transfer efficiency, excellent redox reversibility and low $\cos ^{32-34}$. This compound as mediator were immobilized on the electrodes surface by various methods such as adsorption ${ }^{35}$, simply added to the test solution ${ }^{36}$ or mixing in to carbon paste electrode ${ }^{37}$.

In this study, the activity of 4-chlorocatechol as a homogeneous electrochemical catalyst for electrooxidation of NAC has been investigated at the surface of a glassy carbon electrode (GCE) in buffered aqueous media using various electrochemical methods. Here, a simple and sensitive method was reported for simultaneous voltammetric determination of NAC, UA and Trp based on their reactions with 4-chlorocatechol corresponding quinone.

\section{Experimental}

\section{Reagents and materials}

All solutions were prepared using twice distilled water. Buffer solutions were prepared from orthophosphoric acid and its salts in the $\mathrm{pH}$ range of 4.00 8.00. Stock solutions of NAC, UA and Trp were freshly prepared as required. Potassium chloride from Fluka was used as a supporting electrolyte for all experiments. 4-chlorocatechol, NAC, UA and Trp were from Fluka and were used as received. All other reagents were analytical grade.

\section{Instrumentation}

Electrochemical experiment including cyclic voltammetry (CV), differential pulse voltammetry (DPV) and double-step potential chronoamperometry were recorded with an Autolab potentiostat/galvanostat (PGSTAT30, ECOCHEMIE, Netherlands) controlled by a personal computer. The experimental conditions for voltammetric measurements were controlled with general purpose electrochemical system (GPES). The measurements were carried out using a conventional three electrode cell using an $\mathrm{Ag}|\mathrm{AgCl}| \mathrm{KCl}$ (3 $\mathrm{M})$ electrode as the reference and a Pt wire as the counter (auxiliary) electrode. A digital pH-meter (Ion Analyzer 250, Corning) with precision of \pm 0.001 was used to read the $\mathrm{pH}$ value of the buffered solutions. A glassy carbon disk electrode (Azar electrode Co., Iran) with a geometrical area of $0.0254 \mathrm{~cm}^{2}$, was used as working electrode. The experiments were carried out at room temperature.

\section{RESULTS AND DISCUSSION}

Electrochemical oxidation of 4-chlorocatechol at the surface of GCE

Cyclic voltammograms of $0.5 \mathrm{mM}$ 4-chlorocatechol in $0.1 \mathrm{M}$ phosphate buffer solution ( $\mathrm{pH} 7.00$ ) containing $0.1 \mathrm{M} \mathrm{KCl}$ as a supporting electrolyte at the surface of the GCE at scan rate of potential (v) $20 \mathrm{mV} \mathrm{s}^{-1}$, show one anodic peak and a corresponding cathodic peak which corresponds to transformation of 4-chlorocatechol to 4chloro-1, 2-benzoquinone (Figure 1a). The cyclic voltammogram of bare GCE in $0.1 \mathrm{M}$ blank phosphate buffer solution $(\mathrm{pH} 7.0)$ at scan rate of $20 \mathrm{~m} \mathrm{Vs}^{-1}$ does not show any anodic or cathodic peaks (Figure $1 b)$. 


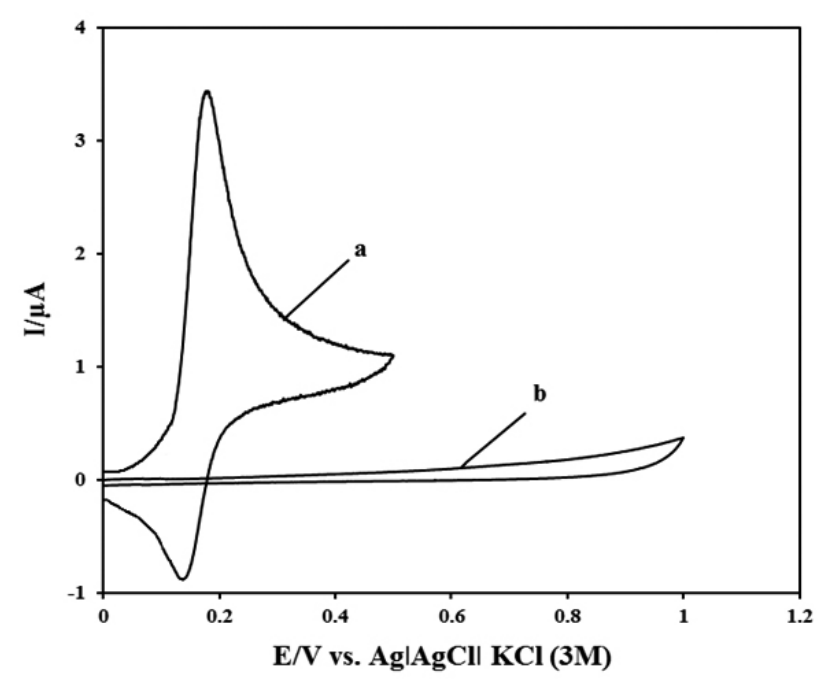

Figure 1: (a) Cyclic voltammogram of $0.5 \mathrm{mM} \mathrm{4-chlorocatechol} \mathrm{at} \mathrm{the}$ surface of GCE in $0.1 \mathrm{M}$ phosphate buffer solution $(\mathrm{pH} 7.0)$ at scan rates of 20 $\mathrm{m} \mathrm{V} \mathrm{s}^{-1}$, Curve (b) as (a) in the absence of 4-chlorocatechol.

Cyclic voltammetry studies of NAC at the surface of GCE in the presence of 4-chlorocatechol

A comparison of the cyclic voltammograms of $0.25 \mathrm{mM}$ 4-chlorocatechol in the $0.1 \mathrm{M}$ phosphate buffered solution $(\mathrm{pH} 7.00)$ in the absence (Figure $2 \mathrm{~b}$ ) and in the presence of $50 \mu \mathrm{M}$ of NAC (Figure 2c) at the surface of GCE, with the cyclic voltammogram of $25 \mu \mathrm{M}$ of NAC at the surface of GCE in $0.1 \mathrm{M}$ blank phosphate buffer solution $\left(\mathrm{pH} \mathrm{7.0)}\right.$ at scan rate of $20 \mathrm{mVs}^{-1}$ (Figure 2a), demonstrated that the electrooxidation of NAC can be catalyzed by 4-chlorocatechol as a homogenous electrochemical catalyst. The oxidation response of NAC at the surface of GCE in the presence of 4-chlorocatechol in comparison with GCE in the absence and in the presence of 4-chlorocatechol, shows a dramatic enhancement in its anodic peak current. Therefore, the oxidation of NAC occurs at a potential about $240 \mathrm{mV}$ versus $\mathrm{Ag}|\mathrm{AgCl}| \mathrm{KCl}(3$ $\mathrm{M})$ in the presence of 4-chlorocatechol at the surface of GCE.

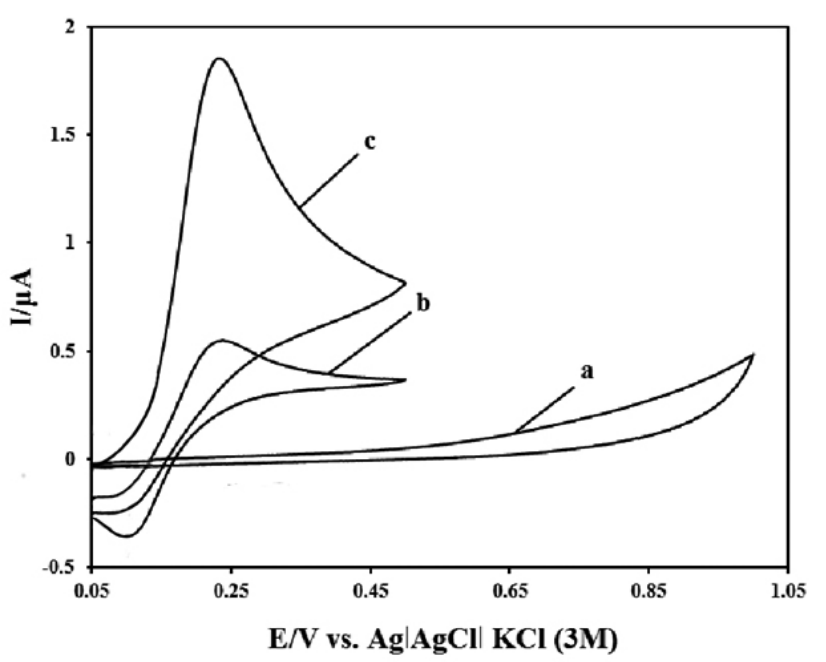

Figure 2: Cyclic voltammograms of (a) $25.0 \mu \mathrm{M} \mathrm{NAC,} \mathrm{(b)} 0.25 \mathrm{mM}$ of 4-chlorocatechol in the absence and (c) presence of $50.0 \mu \mathrm{M}$ NAC in $0.1 \mathrm{M}$ blank phosphate buffer solution ( $\mathrm{pH} 7.0$ ) at the surface of GCE at scan rate of $20 \mathrm{~m} \mathrm{~V} \mathrm{~s}^{-1}$.

The electrooxidation product of 4-chlorocatechol subsequently undergoes a chemical addition reduction process with NAC as a nucleophile agent to produce the reduced adduct compound. In the presence of the thiol moiety in the structure of the product, due to its electron donating property, facilitates the electrooxidation of the additional product and decreases its anodic potential toward less positive potential. As discussed above, this also represented that 4-chlorocatechol can be electrochemically converted to 4-chloro-1, 2-benzoquinone and will readily undergo reaction with thiols possessing sulphydryl group. Hence, the increase in the oxidation peak height is attributed to the oxidation of 4-chlorocatechol-NAC adducts that arises through the electrochemically initiated reaction previously. In fact, once 4-chloro-1, 2 benzoquinone is formed, it could react with a variety of nucleophile reagents, as those possessing sulphydryl $(-\mathrm{SH})$ groups ${ }^{38}$.

In addition, the effect of potential scan rates $\left(10-80 \mathrm{mVs}^{-1}\right)$ on the electrochemical oxidation of NAC in the presence of 4-chlorocatechol was studied at the surface of GCE (Figure 3). The plots of the oxidation peak currents of NAC were linearly depended on the square root of the potential scan rate $\left(v^{1 / 2}\right)$ (Figure 3 inset $\mathrm{A}$ ), which demonstrates a diffusion-controlled electrochemical process. The Tafel slope (Figure 3 inset B) can be obtained from the slope of $E_{\mathrm{p}}$ vs. $\log v$ using following Equation ${ }^{39}$ :

$$
E \mathrm{p}=b / 2 \log v+\text { constant }
$$

The Tafel slope was found to be $0.1188 \mathrm{mV}$ (Figure 3. Inset B), which indicates that a one-electron transfer process is the rate limiting step, and a transfer coefficient $\alpha$, was calculated about 0.38 .

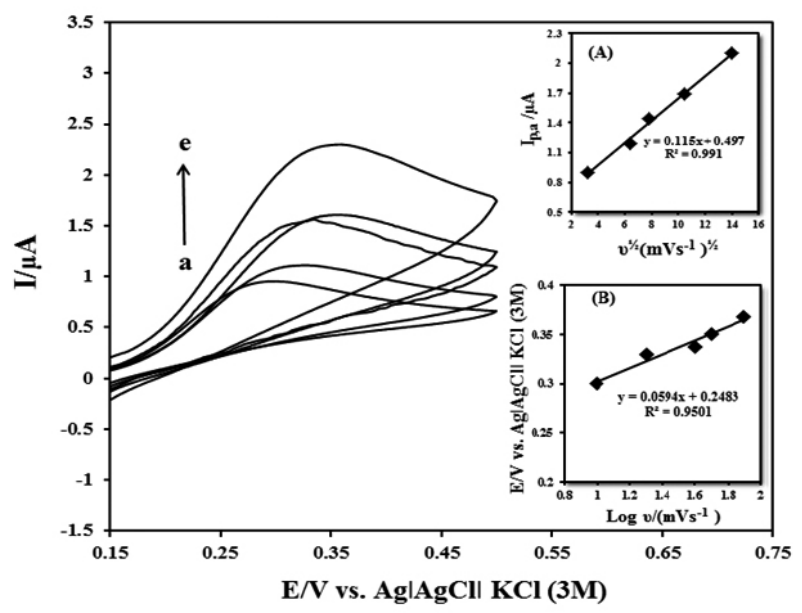

Figure 3: (A) Cyclic voltammograms of $25.0 \mu \mathrm{M}$ NAC in $0.1 \mathrm{M}$ phosphate buffer solution ( $\mathrm{pH} 7.0)$ at the surface of GCE at various scan rates: (a) 10, (b) 20, (c) 40 , (d) 60 and (e) $80 \mathrm{mV} \mathrm{s}^{-1}$. Inset: the plots of $I_{\mathrm{p}, \mathrm{a}}$ vs. $v^{1 / 2}$ (A) and E vs. $\log v$ (B) for $25.0 \mu \mathrm{M}$ NAC.

It is well-known that the electrochemical behavior of 4-chlorocatechol and $\mathrm{NAC}$ are dependent on the $\mathrm{pH}$ value of the aqueous solution ${ }^{40}$. Therefore, $\mathrm{pH}$ optimization of the solution seems to be necessary to obtain the electrooxidation of NAC in the presence of 4-chlorocatechol at the surface of GCE. Thus, we studied the electrochemical behavior of $50 \mu \mathrm{M}$ NAC in $0.1 \mathrm{M}$ phosphate buffered solution at various $\mathrm{pH}$ values $(4.00-8.00)$ in the presence of 0.25 $\mathrm{mM}$ 4-chlorocatechol at the surface of GCE. (Figure 4) As can be seen, the electrooxidation peak of NAC in the presence of 4-chlorocatechol was shifted to a less positive potential with increasing of $\mathrm{pH}$ at the surface of GCE (Figure 4 inset A) and concerning the observed slopes of $-0.061 \mathrm{mV} / \mathrm{pH}$ for NAC, it can be concluded that equal number of electrons and protons are involved in their electrode reactions.

$$
E_{\mathrm{p}, \mathrm{a}}(\mathrm{mV})=-61.0 \mathrm{pH}+0.698\left(R^{2}=0.9823\right)
$$

Figure 4 shows the variation of anodic peak currents of NAC in the presence of 4-chlorocatechol versus $\mathrm{pH}$ values. As the solution $\mathrm{pH}$ was lowered, the thiol functionality was increasingly protonated and hence the nucleophilicity character of the thiol moiety diminished. It can be observed from Figure 4 , that the anodic peak currents of NAC increase with an increase in the solution $\mathrm{pH}$ and in $\mathrm{pH} 7.00$ a maximum anodic peak current was achieved. However in the higher $\mathrm{pH}$, due to the $\mathrm{OH}^{-}$involved in micheal addition and challenge with NAC, anodic peak current of NAC reduced. Therefore, $\mathrm{pH} 7.00$ was chosen as the optimum, which is much closer to physiological $\mathrm{pH}$ value for electrooxidation of NAC in the presence of 4-chlorocatechol at GCE. 


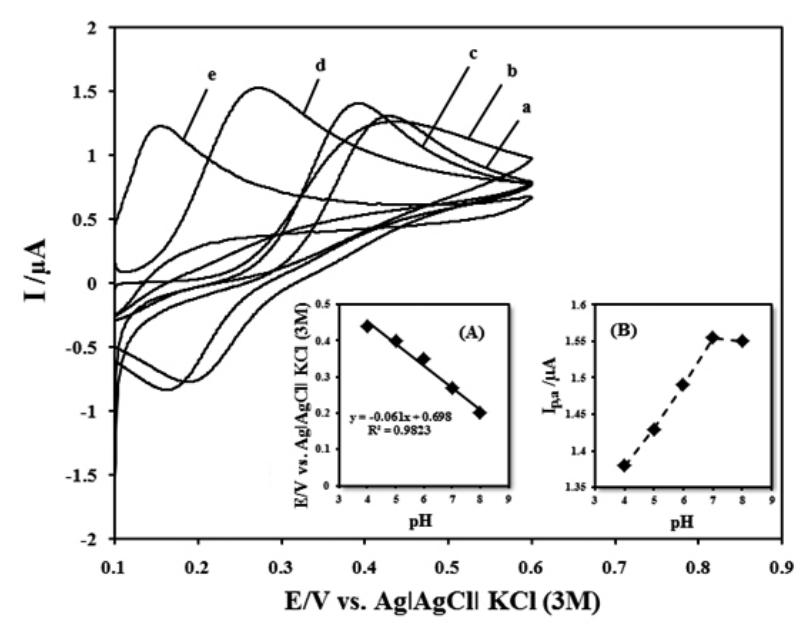

Figure 4: Cyclic voltammograms of $50.0 \mu \mathrm{M}$ NAC in the presence of 0.25 $\mathrm{mM}$ 4-chlorocatechol in $0.1 \mathrm{M}$ phosphate buffer solution at the surface of GCE in the various pHs: (a) 4.0 , (b) 5.0, (c) 6.0 , (d) 7.0 and (e) 8.0 at scan rate $20 \mathrm{mV}$ $\mathrm{s}^{-1}$. Inset: The variation of anodic peak potentials (A) and anodic peak currents (B) versus $\mathrm{pHs}$ values.

\section{Chronoamperometry studies}

Double potential step chronoamperometry as well as other electrochemical methods was employed for the investigation of electrochemical processes Therefore, we studied the electrochemical behavior of NAC in an aqueous buffered solution $(\mathrm{pH} 7.00)$ in the presence of $0.25 \mathrm{mM}$ 4-chlorocatechol at the surface of GCE using chronoamperometry method. Figure 5 shows current time curves of $0.25 \mathrm{mM}$ 4-chlorocatechol in $0.1 \mathrm{M}$ phosphate buffered solution $(\mathrm{pH} 7.00)$ by setting the working electrode potential at $0.2 \mathrm{~V}$ (first potential step) and $0.11 \mathrm{~V}$ (second potential step) versus $\mathrm{Ag}|\mathrm{AgCl}| \mathrm{KCl}$ (3 $\mathrm{M})$ in the presence of various concentrations of NAC. There is not any net cathodic current corresponding to the reduction of 4-chloro-1.2-benzoquinone to 4-chlorocatechol in the presence of NAC, when the second potential step is employed. The oxidation current value increases with increasing of NAC concentration at first potential step. The current corresponding to the electrochemical reaction of an electroactive compound (under diffusion controlled) is described by Cottrell equation ${ }^{41}$ :

$$
I=n F A D_{a p p}^{1 / 2} C_{O} \Pi^{-1 / 2} t^{1 / 2}
$$

where $D_{\text {app }}$ and $C_{0}$ are the apparent diffusion coefficient $\left(\mathrm{cm}^{2} \mathrm{~s}^{-1}\right)$ and the bulk concentration $\left(\mathrm{mol} \mathrm{cm}^{-3}\right)$, respectively. The plot of I versus $\mathrm{t}^{1 / 2}$ was linear (not shown), and from its slope, the mean values of the $D_{\text {app }}$ of NAC was calculated $0.45 \times 10^{-7} \mathrm{~cm}^{2} \mathrm{~s}^{-1}$. As 4-chlorocatechol can act as a homogeneous electrochemical catalyst for electrooxidation of NAC, the rate constant for the chemical reaction $\left(k_{\mathrm{h}}\right)$ can be evaluated by chronoamperometry according to the method described by Galus ${ }^{42}$ :

$$
I_{C} / I_{L}=\Pi^{1 / 2}\left(K_{h} C_{O} t\right)^{1 / 2}
$$

Where $I_{\mathrm{C}}$ is the anodic current in the presence of NAC, $I_{\mathrm{L}}$ is the diffusion limited current in the absence of NAC, and $C_{\mathrm{O}}$ is the initial concentration of NAC in bulk solution. From the slop of $I_{\mathrm{C}} / I_{\mathrm{L}}$ versus $t^{1 / 2}$ plot (Figure 5 , inset), the value of rate constant for chemical reaction between NAC and 4-chloro-1,2 benzoquinone produced from electrooxidation of 4-chlorocatechol, $k_{\mathrm{b}}$ can be simply calculated for a given concentration of substrate. The calculated value of $k$ for NAC is $1.145 \times 10^{3} \mathrm{M}^{-1} \mathrm{~s}^{-1}$, using the slop of $I_{\mathrm{C}} / I_{\mathrm{L}}$ toward $t^{1 / 2}$ plot. The value of $k_{\mathrm{h}}$ explains as well as the sharp feature of peak observed for electrochemical oxidation of NAC in the presence of 4-chlorocatechol at the surface of GCE.

\section{Calibration plot and limit of detection}

DPV method was used to determine the concentration of NAC, UA and Trp in an aqueous. The plot of peak current vs. NAC, UA and Trp concentration consisted of a linear range with slopes of $0.672,1.1949$ and $2.254 \mu \mathrm{A}^{-1} \mathrm{M}^{-1}$ in the concentration ranges of $5.0-45.0 \mu \mathrm{M}, 10.0-50.0 \mu \mathrm{M}$ and $5.0-55.0 \mu \mathrm{M}$, respectively. The detection limits ( $3 \delta$ ) for determination of NAC, UA and Trp were found to be $3.55 \mu \mathrm{M}, 6.96 \mu \mathrm{M}$ and $4.41 \mu \mathrm{M}$.

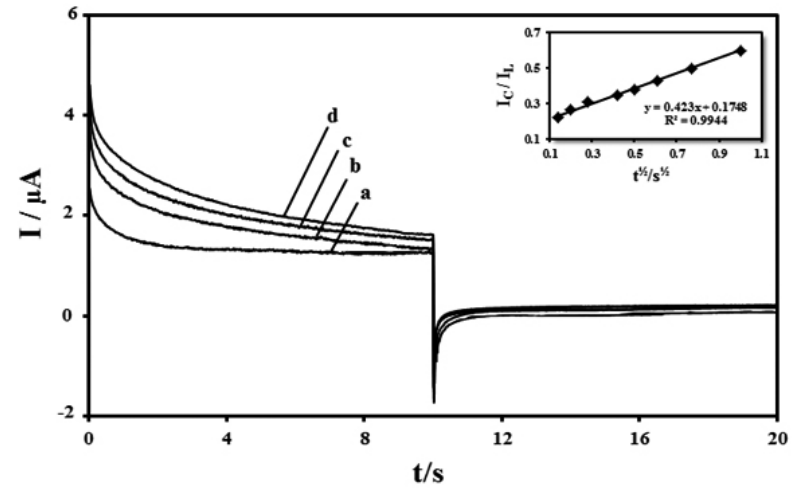

Figure 5: Double step potential chronoamperograms of $0.25 \mathrm{mM}$ 4-Chlorocatechol in the (a) absence and presence of (b) 10, (c) 25 and (d) 50 $\mu \mathrm{M}$ of NAC in $0.1 \mathrm{M}$ phosphate buffer solution ( $\mathrm{pH} 7.00$ ) at the surface of GCE. First and second potential steps were 0.2 and $0.11 \mathrm{~V}$ versus $\mathrm{Ag}|\mathrm{AgCl}| \mathrm{KCl}$ $(3 \mathrm{M})$. Inset: Dependence of $I_{\mathrm{C}} / I_{\mathrm{L}}$ versus of $t^{1 / 2}$ derived from the data of chronoamperograms.

Simultaneous voltammetric determination of NAC, UA and Trp

The main point of this study was the determination of NAC, UA and Trp, simultaneously. This was performed by alternatively changing the concentrations NAC, UA and Trp, and recording their DPV signal. The DPV results showed three well-distinguished anodic peaks at the surface of GCE; therefore the simultaneous voltammetric determination of NAC, UA and Trp was possible at the surface of modified electrode in the present of 4-chlorocatechol (Fig. 6). By contrast, in the absence of 4-chlorocatechol, GCE could not separate the voltammetric signals of NAC, UA and Trp as only one broad oxidation peak was obtained for these three analytes. Table 1 compares these values for UA with values reported by other research groups for electrocatalytic oxidation of these compounds at the surface of various electrodes. A survey of the data reveals that the obtained results from the present electrode are comparable with other modified electrodes for determination of NAC, UA and Trp.
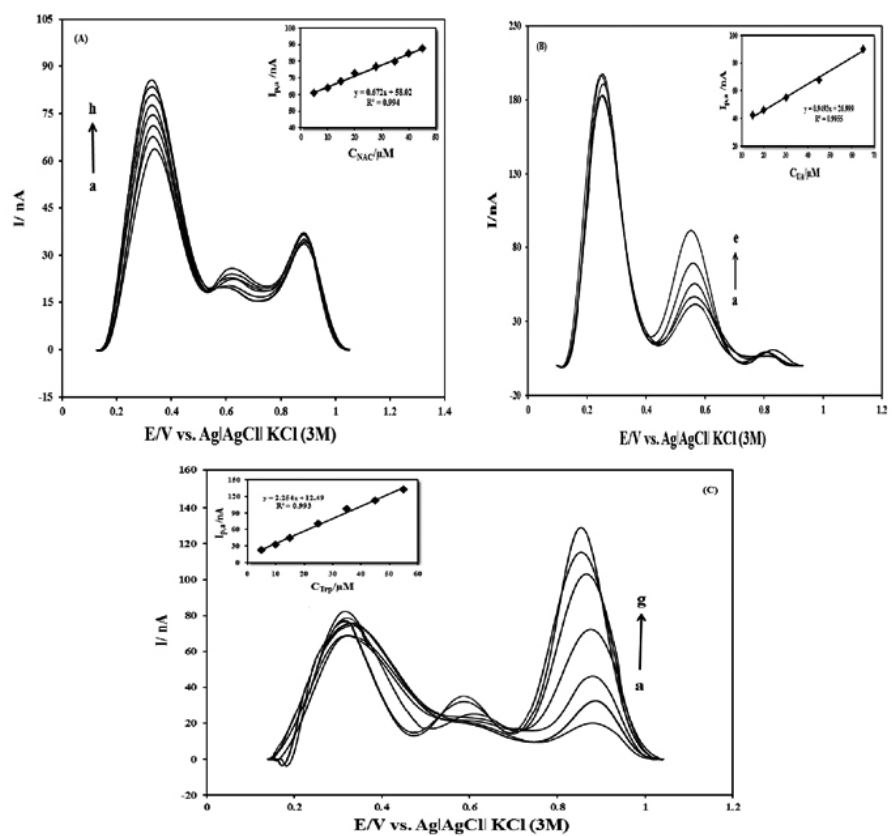

Figure 6: DPV signals for solutions containing of (A) UA $(15.0 \mu \mathrm{M})$, $\operatorname{Trp}(30 \mu \mathrm{M})$ and different concentrations of NAC: (a) 5.0, (b) 10.0, (c) 15.0, (d) 20.0 (e) 30.0 , (f) 35.0 , (g) 40.0, and (h) $45.0 \mu \mathrm{M}$, (B) NAC (0.1mM), Trp $(5.00 \mu \mathrm{M})$, and different concentrations of UA: (a) 10.0, (b) 15.0, (c) 25.0, (d) 35.0 and (e) $50.0 \mu \mathrm{M}$ and (C) NAC $(45.0 \mu \mathrm{M})$, UA $(5.00 \mu \mathrm{M})$ and different concentrations of Trp: (a) 5.0, (b) 10.0, (c) 15.0, (d) 25.0 (e) 35.0, (f) 40, and (g) $55,00 \mu \mathrm{M}$ in $0.1 \mathrm{M}$ phosphate buffer solution ( $\mathrm{pH} 7.0$ ) at the surface of GCE in the present of 4-chlorocatechol. Inset: Calibration plot of peak current vs. (A) NAC concentration, (B) UA concentration and (C) Trp concentration. 
Table 1 : Voltammetric response of different modified electrodes for determination of NAC, UA and Trp.

\begin{tabular}{|c|c|c|c|c|c|c|}
\hline Analyte & Electrode & Modifier & $\mathrm{pH}$ & $\begin{array}{l}\text { Linear } \\
\text { range } \\
(\mu \mathrm{M})\end{array}$ & $\begin{array}{l}\text { Detection limit } \\
\qquad(\mu \mathrm{M})\end{array}$ & References \\
\hline \multirow{4}{*}{ NAC } & $\mathrm{CPE}$ & Catechol & 6.00 & $30.0-2000.0$ & 10.0 & [43] \\
\hline & $\mathrm{CPE}$ & Copper(II) hexacyanoferrate(III) & 6.00 & $120.0-830.0$ & 63.0 & [44] \\
\hline & CPE & $\begin{array}{c}\text { Copper, Nitroprusside Adsorbed on the } 3- \\
\text { Aminopropylsilica }\end{array}$ & 7.00 & $99-890$ & 41.8 & {$[45]$} \\
\hline & GCE & a & 7.00 & $5.0-45.0$ & 3.55 & This study \\
\hline \multirow{3}{*}{ UA } & $\begin{array}{c}\text { Carbon } \\
\text { nanotube paste }\end{array}$ & $\begin{array}{l}\text { 2,2'[1,2ethanediylbis(nitriloethylidyne)]-bis } \\
\text { hydroquinone }\end{array}$ & 7.00 & $25.0-750$ & 8.8 & [46] \\
\hline & GCE & MWCNT-Plys & 7.4 & - & 17.0 & [47] \\
\hline & GCE & a & 7.00 & $10-50$ & 6.96 & This study \\
\hline \multirow{3}{*}{ Trp } & $\begin{array}{c}\text { Carbon } \\
\text { nanotube paste }\end{array}$ & p-aminophenol & 6.00 & $10-300$ & 5.7 & [48] \\
\hline & $\mathrm{CPE}$ & $\begin{array}{l}2,2^{\prime}[1,2 \text { ethanediylbis(nitriloethylidyne)]-bis } \\
\text { hydroquinone }\end{array}$ & 7.00 & - & 12.3 & [49] \\
\hline & GCE & $\mathrm{a}$ & 7.00 & $5-55$ & 4.41 & This study \\
\hline
\end{tabular}

Interference studies

The interference effect was studied on the analysis signal of NAC. Various possible interfering substances, such as dopamine, acetaminophen and ascorbic acid were examined for their effect on the voltammetric determination of NAC under the optimum conditions. The results showed there was no substantial change in the peak current of NAC in the absence and presence of these interfering agents. The data are summarized in Table 2.

Table 2: Effect of different interferes on the voltammetric signal of NAC at the surface of GCE in the present of 4-chlorocatechol.

\begin{tabular}{|c|c|c|}
\hline \multirow{2}{*}{ Interfering agent } & $\begin{array}{c}\text { Concentration } \\
(\mu \mathrm{M})\end{array}$ & Signal change (\%) \\
\hline Dopamine & 75.0 & -0.34 \\
\hline Acetaminophen & 100.0 & -0.27 \\
\hline Ascorbic acid & 50.0 & -0.40 \\
\hline
\end{tabular}

Determination of NAC in pharmaceutical preparations

The ability of the purposed method for voltammetric determination of NAC was employed the voltammetric determination of NAC in real sample. Tablet solutions were prepared from thoroughly grinding and mixing a tablet of NAC (labeled $600 \mathrm{mg}$, Avicenna Co., Saveh, Iran). An adequate amount of the obtained fine powder dissolved in $0.1 \mathrm{M}$ phosphate buffer $\mathrm{pH} 7.0 \mathrm{using}$ an ultrasonic bath for $5 \mathrm{~min}$. Different amounts of each solution were transferred into the $10.0 \mathrm{~mL}$ voltammetric cell and analyzed by standard addition method. The results show that the present method is credible for the quantification of NAC in pharmaceutical samples. The obtained results are shown in Table 3.

Table 3: Results obtained for N-acetyl-L-cysteine determination in pharmaceutical formulation $(\mathrm{n}=3)$

\begin{tabular}{|c|c|c|c|c|c|c|}
\hline Sample & Added (mM) & Found (mM) & Recovery (\%) & R.S.D (\%) & Labelled claim (mg) & $\begin{array}{l}\text { MeanAmount } \\
\text { found (mg) }\end{array}$ \\
\hline 2 & 0.4 & 0.384 & 96 & 0.008 & 600 & 564 \\
\hline
\end{tabular}

\section{CONCLUSIONS}

An electrochemical study step by step was presented on the electrooxidation of 4-chlorocatechol as a homogenous electrochemical catalyst for simultaneous determination of NAC, UA and Trp at the surface of GCE in buffer aqueous medium. The reaction was applied successfully for the selective simultaneous voltammetric determination of NAC, UA and Trp in aqueous media; due to an increase in the anodic current attributed to the reoxidation of the thiol addition product. Also, it could be exploited as means of quantifying the concentration of the NAC, UA and Trp. This homogeneous electrochemical catalyst showed to be promising for NAC, UA and Trp determination with many desirable properties including high sensitivity, low detection limit and decrease in overvoltage for the electrochemical oxidation of these compounds. Nevertheless, the electrode was reliable, simple, rapid to prepare, low cost, precise and did not require extensive preliminary sample treatment.

\section{REFERENCES}

1. M. R. Holdiness, Clin. Pharmacokinet., 20, 123 (1991).

2. V. Mollace, BMC Neurosci., 8, 106 (2007).

3. M. Liu, M. Wikonkal and D. E. Brash, Carcinogenesis, 20, 1869 (1999).

4. P. N. R. Dekhuijzen, Eur. Respir. J., 23, 629 (2004).

5. R. Breitkreutz, N. Pittack, C. T. Nebe, D. Schuster, J. Brust, M. Beichert, and V. Hack, J. Mol. Med., 78, 55 (2000).

6. V. Valcour and B. Shiramizu, Mitochondrion, 4, 119 (2004).

7. A. L. Fu, Z. H. Dong and M. J. Sun, Brain Res, 1109, 201 (2006).

8. M. C. G. Alvarez Coque, M. J. M. Hernandez, R. M. Camanas and C. M. Fernandez, Analyst, 114, 975 (1989).

9. M. A. Raggi, V. Cavrini and A. M. Dipietra, J. Pharm. Sci., 71, 1384 (1982).

10. W. T. Suarez, H. J. Vieira and O. Fatibello-Filho, J. Pharm. Biomed. Anal., 
37, 771 (2005)

11. W. T. Suarez, H. J. Vieira and O. Fatibello-Filho, Acta. Chim. Slov., 52, 164 (2005).

12. V. Concha-Herrera, J. R. Torres-Lapasio and MC Garcia-Alvarez-Coque, J. Liq. Chromatogr. Relat.Technol., 27, 1593 (2004).

13. D. Tsikas, J. Sandmann, M. Ikic, J. Fauler, D. O. Stichtenoth and J. C. Frolich, J. Chromatogr. B, 708, 55 (1998).

14. F. Y. Tsai, C. J. Chen and C. S. Chien, J. Chromatogr. A, 697, 309 (1995).

15. S. M. Al-Ghannam, A. M. El-Brashy, B. M. Al-Farhan, Farmaco, 57, 625 (2002).

16. M. Trojanowicz, Anal. Chem., 25, 480 (2006).

17. T. M. Devlin, Text book of Biochemistry with Clinical Correlations, Wiley-Liss, New York, 1992.

18. V. S. E. Dutt, H. A. Mottola, Anal. Chem., 46, 1777 (1974).

19. J. Arguello, H. A. Magosso, T. C. Canevari, R. Landers, Y. Gushikem, Electroanalysis, 23, 334 (2011).

20. M. Mazloum-Ardakani, H. Beitollahi, M. K. Amini, B. B.F. Mirjalili, F. Mirkhalaf, J. Electroanal. Chem., 651, 243 (2011).

21. A. Babaei, D. J. Garrett, A. J. Downard, Electroanalysis, 23, 417 (2011).

22. Y. Wang, L. L. Tong, Sens. Actuators B, 150, 43 (2010)

23. H. Beitollahi, M. Mazloum Ardakani, H. Naeimi, B. Ganjipour, J. Solid State Electrochem., 13, 353 (2009).

24. Z. Gao, K.S. Siow, A. Ng, Y. Zhang, Anal. Chim. Acta, 343, 49 (1997).

25. G. N. Chen, Z.F. Zhao, X.L.Wang, J.P. Duan, H.Q. Chen, Anal. Chim. Acta, 452, 245 (2002).

26. G. Chen, J. S. Cheng, J.N. Ye, J. Fresenius, Anal. Chem., 370, 930 (2001)

27. E. Heftmann, Chromatography, Fundamentals and Applications of Chromatography and Related Differential Migration Methods, Part B: Applications, fifth ed., Elsevier, Amsterdam, 1992.

28. C. G. Nan, Z. Z. Feng, W. X. Li, D. J. Ping and C. H. Qin, Anal. Chim. Acta, 452, 245 (2002).

29. D. R. Baker, Capillary Electrophoresis, Wiley, New York, 1995.
30. W. J. M. Underberg, J. C. M. Waterval, Electrophoresis, 23, 3922 (2002).

31. J. Huang, X. Xing, X. Zhang, X. He, Q. Lin, W. Lian and H. Zhu, Food Res. Int., 44, 276 (2011).

32. A. Salimi and R. Hallaj, Electroanalysis, 16, 1964 (2004).

33. P. V. A. Pamidi, J. Wang, Electroanalysis, 8, 244 (1996).

34. S. M. Golabi and H. Zare, Electroanal. Chem., 465, 168 (1994).

35. F. Pariente, F. Tobalina, G. Moreno, L. Hemandez, E. Lorenzo, H. D. Abruna, Anal. Chem., 69, 4065 (1997).

36. N. S. Lawrence, J. Davis, R. G. Compton, Talanta, 53, 1089 (2001).

37. H. R. Zare and N. Nasirzadeh, Electroanal., 18, 507 (2006).

38. W. S. Pierpoint, Biochem. J., 98, 567 (1996).

39. J. A. Harrison and Z. A. Khan, J. Electroanal. Chem., 28, 131 (1970).

40. T. R. Ralph, M. L. Hitchman, J. P. Millington and F. C. Walsh, J. Electroanal. Chem., 375, 1 (1994).

41. R. Greef, R. Peat, L. M. Peter and D. Pletcher, J. Robinson, Instrumental Methods in Electrochemistry, Ellis Horwood, Chichester, UK, 1990.

42. Z. Galus, Fundamentals of electrochemical analysis, Ellis Horwood Press, New York, 1994.

43. J. Raoof, R. Ojani, M. Amiri-Aref, F. Chekin, J. Appl. Electrochem., 40, $1357(2010)$

44. W.T. Suarez, L.H. Marcolino Jr., O. Fatibello-Filho, Microchem. J., 82, 163 (2006).

45. A. C. Sa, L., L. Paim, U. O. liveira Bicalho, D. R. Carmo, Int. J. Electrochem. Sci., 6, 3754, (2011).

46. H. Beitollahi, M. Mazloum-Ardakani, B. Ganjipour, H. Naeimi, Biosens. Bioelectron., 24, 326 (2008).

47. M.C. Rodrígueza, J. Sandovalb, L. Galiciac, S. Gutiérrezd, G.A. Rivas, Sensors and Actuators B, 134, 559, (2008).

48. AA. Ensafi, S. Dadkhah-Tehrani, H. Karimi-Maleh, Anal Sci., 27, 409, (2011).

49. M. Mazloum-Ardakania, B. Ganjipourb, H. Beitollahia, M. K. Aminid, F. Mirkhalafe, H. Naeimif, M. Nejati-Barzokif, Electrochimica Acta, 56, 9113, (2011). 